\title{
Evaluating Sovereign Disaster Risk Finance Strategies: A Framework
}

\author{
Daniel J. Clarke ${ }^{\mathrm{a}}$, Olivier Mahul ${ }^{\mathrm{b}}$, Richard Poulter ${ }^{\mathrm{b}}$ and Tse-Ling Teh $^{\mathrm{c}}$ \\ ${ }^{a}$ Government Actuary's Department, London, UK. \\ E-mail: daniel.clarke@gad.gov.uk \\ ${ }^{\mathrm{b}}$ Finance and Markets Global Practice, World Bank, Washington, DC, USA. \\ ${ }^{\mathrm{c}}$ Grantham Research Institute on Climate Change and the Environment, The London School of Economics and \\ Political Science, London, UK.
}

This paper proposes a framework for ex ante evaluation of sovereign disaster risk finance instruments available to governments for funding disaster losses. The framework can be used by governments to help choose between different financial instruments, or between different combinations of instruments, to achieve appropriate and financially efficient strategies to fund disaster losses. In doing so, the framework takes into account the risk of disasters, economic conditions and political constraints. The paper discusses the framework in the context of a hypothetical country, with parameters selected to represent a disaster-prone small island state. The paper shows how a mix of instruments can be chosen to minimise the economic opportunity cost given the underlying disaster risk faced and prevailing economic and financial conditions. The Geneva Papers (2017) 42, 565-584. doi:10.1057/s41288-017-0064-1

Keywords: disaster risk financing; natural hazards; financial analysis; insurance; contingent credit

The online version of this article is available Open Access

Article submitted 22 September 2016; accepted 21 June 2017; published online 11 September 2017

\section{Introduction}

As the frequency and severity of climate extremes continue to rise, extreme natural events are an increasing drain on public finances. In post-disaster situations, the requirements for critical and rapid expenditures to support the recovery of people and economies and the reconstruction of public infrastructure can lead to governments using slow or expensive instruments, such as budget reallocations or borrowing on unfavourable terms. ${ }^{1}$ In an attempt to be better financially prepared for when disasters occur, governments are increasingly interested in implementing comprehensive sovereign disaster risk finance strategies, defined by World Bank Group (2014) as "the bringing together of pre- and post-disaster financing instruments that address the evolving need of funds-from emergency response to long-term reconstruction - and are appropriate to the relative probability of events". Ministries of finance of disaster-prone countries, along with donor partners who are also facing rising costs due to disasters, are increasingly asking questions such as the following:

\footnotetext{
${ }^{1}$ Benson and Clay (2004).
} 
- Should we set aside funds in a reserve fund, and how large should this reserve fund be?

- How much reliance should be placed on emergency reallocations of funds away from other parts of our budget to finance disaster losses?

- Should we seek to establish a line of credit which can immediately be drawn upon if a disaster were to occur?

- How can we evaluate proposals for risk transfer products such as disaster insurance or catastrophe bonds?

The increasing need for appropriate instruments to finance disaster risk has resulted in tremendous growth in the number and type of financial and budgetary instruments available. This has led to further confusion amongst many governments and donors as to how such products can be compared and combined. Very little evidence exists to guide how comprehensive strategies of different instruments should be designed and compared, and a coherent quantitative framework for ex ante evaluation of the economic cost of these budgetary and financial instruments does not exist in a formalised way. At present, an increasing number of governments are executing large financial transactions with the intention of improving their financial protection against disasters. However, such transactions may be executed without a systematic analysis of whether the programs and financial strategies being employed are appropriate and cost-effective, bearing in mind the risks faced.

One of the challenges in setting out such a quantitative framework for evaluation of potential risk financing investments is the cash budget mindset that pervades traditional thinking about financing disaster response. Many governments and donors operate with something that resembles a cash budget (spending the full resources that are available) and, for them, buying an insurance product or arranging a line of contingent credit would provide more fiscal space in the aftermath of a disaster, allowing them to mount a larger response. With this sort of approach in the evaluation of potential risk, financing instruments would have to take into account both the cost-efficiency of the financing structure and the fact that the total amount of finance available depends on the instruments used. Evaluating alternative financial instruments is challenging if there exists significant uncertainty over the expenditures that would be made following a disaster, particularly if such expenditures depend on the source of finance used.

The main innovation of this paper is to use insights from actuarial science and financial economics to divide the problem in a way that makes ex ante evaluation of the financing side of the problem tractable. Specifically, we demonstrate the power of making an assumption that a government has chosen the level of expenditure it would make following every possible future disaster, and restrict ourselves to comparing risk financing strategies that fully finance these expenditures. In finance terms, we are assuming that the government has chosen a fixed contingent liability and wishes to understand the costs and benefits of financing this contingent liability in different ways. The problem is then comparable to risk management practices employed in the private financial sector, where financial sector regulation requires financial institutions to clarify their contingent liability and ensure that it is fully financed. The weakness of this approach is that it does not provide insight over what government should and shouldn't do post-disaster. However, by abstracting from this question, it does allow careful comparative examination of potential financial strategies. 
This paper then explores the questions of whether and how a government can design a combination of financial instruments to cost-effectively finance this fixed contingent liability. It proposes a conceptual framework including simple, implementable formulae which allow governments to assess the expected opportunity cost of sovereign risk financing strategies. Such strategies include one or more of the following budgetary and financial instruments:

- risk transfer instruments such as indemnity or parametric insurance, catastrophe swaps or catastrophe bonds;

- reserves or ring-fenced ex ante budget allocations for financing disaster losses;

- contingent credit at concessional interest rates, such as the World Bank Development Policy Loan with Catastrophe Deferred Drawdown Option (CAT-DDO) or the Stand-by Emergency Credit for Urgent Recovery (SECURE) offered by the Japanese International Coordination Agency (JICA);

- emergency ex post reallocations from other parts of the government budget; and

- ex post borrowing in the commercial market.

The World Bank has recommended a tiered approach to disaster risk financing-a strategy formed of different financial instruments for different layers of risk-as appropriate and cost-effective. ${ }^{2}$ Evidence also suggests that insurance and insurance-like instruments such as catastrophe bonds can protect the national budget and improve the speed at which capital is available and expenditure is undertaken, reducing the economic impact of natural disasters. ${ }^{3}$ While previous work has been done to support this tiered approach, ${ }^{4}$ this paper aims to consolidate previous work into a single coherent and practically implementable framework, while also providing insight into how to determine the point at which one financial instrument becomes more cost-effective than another for a given layer of risk. This paper builds on an existing literature on the pricing of risk transfer instruments ${ }^{5}$ along with some earlier work on the opportunity cost of contingent credit. ${ }^{4}$ We also draw upon the notion of opportunity cost as developed through the literature on cost-benefit analysis. The proposed framework provides quantitative evidence that using different financial instruments in combination can be the most cost-efficient way to finance a government's chosen contingent liability following a disaster.

Furthermore, the proposed framework provides a methodology for determining the sovereign risk financing strategy which minimises the average cost, or the strategy which minimises the cost of financing losses at a given return period. This allows the framework to provide useful insights for decision-makers who wish to minimise average costs, or for those who wish to minimise the cost of financing a disaster of particular magnitude. For decision-makers with other financial objectives, the framework may still be a useful input into the decision-making process where the cost trade-offs between different financial instruments are an important consideration.

The remainder of the paper is structured as follows: The next section proposes a theoretical framework for ex ante evaluation of the cost of alternative risk financing

\footnotetext{
2 Gurenko and Mahul (2003); Ghesquiere and Mahul (2010); GFDRR and World Bank Group (2014).

${ }^{3}$ Goes and Skees (2003); Linnerooth-Bayer and Mechler (2007); de Janvry et al. (2016).

${ }^{4}$ For example, Clarke and Mahul (2011).

${ }^{5}$ Kreps (1990); Lakdawalla and Zanjani (2006); Lee and Yu (2002, 2007).
} 
strategies. We demonstrate that under quite general conditions a layered financial strategy is optimal and propose formulae for the opportunity cost of financial instruments, leading to the optimal risk financing strategy for a risk neutral government. The third section illustrates a practical application of the framework, focusing on a country case study which highlights how a country's economic situation and hazards faced are key factors in determining the structure of a cost-effective risk financing strategy. The fourth section provides a discussion of the results of the presented case study and also other applications of the framework, policy implications, limitations of the framework and other considerations. The final section concludes and provides some suggestions for further research in this area.

\section{A model of disaster risk finance}

In this section, we set out a basic model of sovereign disaster risk financing, with a government structuring a one-year strategy to finance a well-defined contingent liability. The model has two phases - a phase before the start of the year where the government may arrange financial and budgetary instruments, and a post-disaster phase, at the start of the year, where the size of the disaster is revealed and the government decides which financial and budgetary instruments to utilise to finance expenditures.

\section{Risk financing strategies}

The government is exposed to an uncertain loss, realised at the start of the year. Consider a government that chooses to finance a different level of total expenditure $x \in[0, \bar{x}]$ in each possible state. We denote states by the expenditure $x$. We assume that the distribution of $x$ has no atoms and denote the probability and cumulative density functions by $f$ and $F$, respectively.

Government has access to five potential instruments, indexed $j \in\{1,2,3,4,5\}$, as follows:

1. Reserve fund (or ex ante budget allocation);

2. Line of contingent credit;

3. Emergency ex post budget reallocation;

4. Ex post sovereign borrowing; and

5. Insurance (or other risk transfer instrument).

We consider a two-period model where in the first period, before the state of the world is realised, the government can arrange a maximum amount of financing $\bar{\theta}_{j}$ for each instrument $j$. In the second period, after the state of the world is realised, the government may then choose how much of each financial instrument to use to finance expenditures, $\theta_{j}(x)$. The government cannot use more of a financial instrument than it has pre-arranged, that is $\theta_{j}(x) \leq \bar{\theta}_{j}$ for all $j, x$.

A risk financing strategy is therefore a set $(\bar{\theta}, \theta)=\left(\left\{\bar{\theta}_{j}, \theta_{j}(x)\right\}_{j \in\{1,2 \ldots 5\}, x \in[0, \bar{x}]}\right)$, and we may define an actuarially sound risk financing strategy as follows. 
Definition 1 A risk financing strategy $(\bar{\theta}, \theta)$ is actuarially sound if it precisely finances the contingent liability, that is, $\sum_{j=1}^{5} \theta_{j}(x)=x$ for all $x$.

\section{Opportunity cost of risk financing instruments}

We may now present the risk financing instruments to be considered and characterise the realised cost $C_{j x}$ of each instrument using the economic notion of opportunity cost. $^{6}$ All opportunity costs are taken to be the economic cost of using each instrument to fund the specified disaster expenditures. Costs are presented in units of expenditure at the start of the year, with future expenditures discounted using an annual effective interest rate $i$ which we take to be the marginal rate of ex ante borrowing. As is common in financial theory, we assume that $i$ is set to be the marginal interest rate on sovereign debt.

Reserve fund $(j=1)$

Any reserve or contingency fund is assumed to be set up at the beginning of a government's fiscal year, held in liquid funds and only disbursed in the event of a disaster. A budget allocation which is ring-fenced for disaster response activities is assumed to work in the same way, although, in practice, the funds may be held within government accounts rather than liquid money market instruments.

The maximum utilisation of a reserve fund is just the size of the reserve fund, which we denote by $\bar{\theta}_{1}$.

We denote the cost of funds to capitalise the reserve fund by $\delta$. A government can finance the reserve fund either by borrowing from the commercial market or by reallocating budget from other planned investments. In the former case, $\delta$ is just the interest rate of additional commercial borrowing, and we assume that the debt used to finance the reserve fund can be repaid at the end of the year at no frictional cost, for example, by restructuring debt. ${ }^{7}$ In the latter case, $\delta$ denotes the social rate of return on forgone public investments, and we assume that the investments can be delayed by a year with no change to their costs and benefits. The investment return on unspent funds is assumed to be an effective rate of $r$, earned over the course of the year and so the net cost of unspent funds is $(1+\delta)-(1+r)=\delta-r$, payable at the end of the year, and the cost per unit of spent funds is $(1+\delta)$, also payable at the end of the year. Discounting both of these costs to the start of the year gives a realised opportunity cost, discounted to the start of the year, of

$$
C_{1}(x)=\left(\frac{\delta-r}{1+i}\right) \times\left(\bar{\theta}_{1}-\theta_{1}(x)\right)+\left(\frac{1+\delta}{1+i}\right) \times \theta_{1}(x) .
$$

\section{Line of contingent credit $(j=2)$}

Lines of contingent credit are pre-arranged loans which can be drawn down in times of financial crises. They are available from the World Bank, the IMF, developmental banks and other multilateral financial institutions, other national governments and also from commercial lenders.

\footnotetext{
${ }^{6}$ Buchanan (2008).

${ }^{7}$ In the case where the reserve fund is debt-financed, there could be situations in which $\delta>i$ where, for example, the additional borrowing shifts the government's marginal cost of borrowing.
} 
The maximum utilisation of the line of credit is just the maximum amount that can be drawn down, which we denote by $\bar{\theta}_{2}$. The upfront fee for contingent credit per unit of credit arranged, payable at the start of the year, is denoted $\kappa$, and $c \leq i$ is the interest rate payable on drawn-down balances. As for the debt-financed reserve fund, we assume that any drawndown contingent credit can be repaid at the end of the year at no frictional cost, for example by restructuring debt.

One interesting feature of some lines of contingent credit, such as the World Bank's Development Policy Loan with Catastrophe Deferred Drawdown Option (Cat DDO), is that they are available at below-market rates, that is, with $c<i$, and cheap contingent credit reduces the amount of cheap direct credit available to government. To capture this, we may assume that, for every unit of contingent credit at interest rate $c$, the amount of direct credit available to the government at interest rate $c$ reduces by $\beta \bar{\theta}_{2}$ for some $\beta \in\{0,1\} . \beta=1$ would correspond to full crowding out of cheap credit, as for the World Bank's IBRD Cat DDO if a government was planning to utilise its full IBRD lending envelope. Hence, purchasing a Cat DDO reduces their ability to borrow the full envelope upfront. $\beta=0$ would correspond to commercial contingent credit, or a Cat DDO if a government was not otherwise planning to utilise its full IBRD lending envelope.

There are therefore three components to our formula for the opportunity cost of contingent credit. First there is a fee of $\kappa$ per unit of contingent credit arranged, payable at the start of the year. Second, the amount the government is able to borrow at interest rate $c$ has been reduced by $\beta \bar{\theta}_{2}$ and so, this amount must be borrowed at its marginal interest rate of $i$, resulting in a net cost at the end of the year of $\beta(i-c) \bar{\theta}_{2}$. Third, for any expenditures actually financed by the contingent credit, there is a cost of $(1+c)$ payable at the end of the year. Discounting these costs to the start of the year gives a realised opportunity cost, discounted to the start of the year, of

$$
C_{2}(x)=\kappa \bar{\theta}_{2}+\beta\left(\frac{i-c}{1+i}\right) \bar{\theta}_{2}+\left(\frac{1+c}{1+i}\right) \theta_{2}(x) .
$$

\section{Emergency ex post budget reallocation $(j=3)$}

A common solution for governments to finance disaster response, recovery and reconstruction is to divert funds away from public services and ongoing public projects. ${ }^{8}$ However, anecdotal evidence suggests that such reallocations are typically from operations and maintenance budgets and can be very costly for development. For example, a budget reallocation from the health-care budget to disaster response may lead to no change in the health infrastructure or wage bill, but hospitals may be left without electricity or supplies for long periods of time.

We assume that unlimited emergency budget reallocations are possible in the event of a disaster and that these reallocations do not cover any upfront cost borne before the disaster. This is likely to be quite unrealistic in practice as there are typically limits to the ability of government to reallocate budgets quickly after a disaster. Moreover, systematically relying on budget reallocations to finance post-disaster expenditures would have direct non-linear welfare costs, and possibly, also indirect non-linear costs arising from ex ante behavioural

\footnotetext{
${ }^{8}$ Bevan and Cook (2014).
} 
changes of households, firms and public service providers responding to uncertainty in public services and infrastructure. However, we make this assumption for now, and discuss how the results would change if it were relaxed in the section "Discussion of Results".

We assume that government projects not implemented due to funds being diverted towards disaster-related expenditures would be implemented in the following year; thus the government only forgoes one year of social returns relative to the situation where they do not engage in budget reallocations.

Denoting the social rate of return on projects that budget is reallocated away from as $h \geq i$, the realised opportunity cost discounted to the start of the year is

$$
C_{3}(x)=\left(\frac{1+h}{1+i}\right) \theta_{3}(x) .
$$

Bevan and Adam ${ }^{9}$ present a methodology for estimating $h$, building on a computable general equilibrium model of the economy.

Ex post sovereign borrowing $(j=4)$

Finally, we consider the possibility of government financing expenditures by issuing additional debt in the aftermath of a disaster. This can be slow-in many countries it can take more than nine months between disaster and additional loans-leading to delayed response and greater human and economic costs of the disaster. It can also be quite costly if interest rates are high in a post-disaster environment (although the evidence for whether disasters cause an increase in sovereign borrowing rates is inconclusive). We therefore assume that the pre-disaster level of indebtedness is taken into account in the interest rate paid by government, but this rate does not change with the amount of additional debt issued.

We assume that unlimited ex post sovereign borrowing is possible in the event of a disaster at interest rate $e$, repayable in equal installments over $n$ years, and that this borrowing does not lead to any upfront cost borne before the disaster. However, we allow for the possibility that ex post direct credit is slow, which increases the total economic cost of the planned expenditures by $(1+d)^{t}$, where $d$ denotes the annual effective increase in cost due to the delay and $t$ denotes the length of the delay in years. Discounting debt repayments to the start of the year gives a realised opportunity cost, discounted to the start of the year, of:

$$
C_{4}(x)=\left(\frac{1+d}{1+i}\right)^{t} \frac{a_{\bar{n} \mid i}}{a_{\bar{n} \mid e}} \theta_{4}(x),
$$

where $a_{\bar{n} \mid \gamma}=\frac{1-(1+\gamma)^{-n}}{\gamma}$ is an annuity immediate at rate $\gamma$ payable in arrears over $n$ years.

\section{Insurance $(j=5)$}

For insurance, the government is able to choose a claim payment schedule that precisely matches its planned expenditures, and so we use $\theta_{5}(x)$ to represent the claim payment. The cost of insurance is simply the premium, and we assume that this is fully payable upfront at the start of the year. The insurance is priced using a fixed multiple $m$, that is,

\footnotetext{
${ }^{9}$ Bevan and Adam (2016).
} 


$$
C_{5}(x)=m \int_{0}^{\bar{x}} f(x) \theta_{5}(x) \mathrm{d} x
$$

This linear pricing formula for insurance is quite crude, and is not fully consistent with the way that insurance markets price risk, but is assumed here for simplicity. We assume that insurance pays claims as expenditures fall due without delay, or if there are delays that the cost of any delay is included within the pricing multiple $m$. In the section "Discussion of results", we discuss how different pricing formulae would change the theoretical and quantitative results.

\section{Optimal risk financing strategies for risk neutral governments}

The framework assumes that the government has chosen what expenditure they would make following every possible future disaster and, therefore, we compare alternative risk financing strategies that are assumed to fully finance the chosen contingent liability $x$. Let us now assume that the government seeks to finance its chosen contingent liability by minimising the expected total opportunity cost of financing. ${ }^{10}$ Adding Eqs. (1)-(5) and integrating over all potential expenditures allows us to rewrite the total expected cost of strategy $(\bar{\theta}, \theta)$ as

$$
C(\bar{\theta}, \theta)=\sum_{j=1}^{5}\left[a_{j} \bar{\theta}_{j}+\int_{0}^{\bar{x}} f(x) b_{j} \theta_{j}(x) \mathrm{d} x\right]
$$

where $a_{j}$ and $b_{j}$ are constants that do not depend on $x$ (Table 1).

And the government's optimisation problem may be written as

$$
\min _{\bar{\theta}, \theta} C(\bar{\theta}, \theta) \text { subject to } \theta_{j}(x) \leq \bar{\theta}_{j} \text { for all } j, x \text { and } \sum_{j=1}^{5} \theta_{j}(x)=x \text { for all } x
$$

We may now begin to characterise the solution to this optimisation problem. First let us define a layered risk financing strategy.

Definition 2 A risk financing strategy $(\bar{\theta}, \theta)$ is layered if there exists $\gamma_{j}$ for $j \in\{1,2 \ldots .5\}$ such that we may write $\theta_{j}(x)=\max \left(0, \min \left(\bar{\theta}_{j}, x-\gamma_{j}\right)\right)$ for all $j$.

Layering here describes the situation where one instrument is used until exhausted before the next instrument is engaged. For example, "instrument $X$ will finance the first $L_{X}$ of any expenditures, then instrument $Y$ will finance the next $L_{Y}$, then instrument $Z$ will finance the next $L_{Z}$, etc."

Lemma 1 A layered risk financing strategy minimises expected costs.

\footnotetext{
${ }^{10}$ This may be an unrealistic assumption for some governments who are averse to budget volatility (Ghesquiere and Mahul 2007).
} 
Table 1 Cost parameters of different risk financing instruments

\begin{tabular}{llll}
\hline$j$ & Instrument & $a_{j}$ & $b_{j}$ \\
\hline 1 & Reserve fund & $\frac{\delta-r}{1+i}$ & $\frac{1+r}{1+i}$ \\
2 & Line of contingent credit & $\kappa+\beta \frac{i-c}{1+i}$ & $\frac{1+c}{1+i}$ \\
3 & $\begin{array}{l}\text { Emergency ex post budget } \\
\text { reallocation }\end{array}$ & 0 & $\frac{1+h}{1+i}$ \\
4 & Ex post sovereign borrowing & 0 & $\left(\frac{1+d}{1+i}\right)^{t} a_{a n i}$ \\
$a_{n \mid e}$ \\
5
\end{tabular}

Proof Consider minimising equation $C(\bar{\theta}, \theta)$ for fixed $\bar{\theta}$, that is to say after the decisions have been made about how much of each instrument to pre-arrange. If we can demonstrate that there exists a layered risk financing strategy $\theta$ that minimises $C(\bar{\theta}, \theta)$ for fixed $\bar{\theta}$, then clearly a layered financing strategy must also be a solution to minimisation problem (7), and we are done.

Now, for fixed $\bar{\theta}, C(\bar{\theta}, \theta)$ will be minimised by a strategy that minimises

$$
\int_{0}^{\bar{x}} f(x) \sum_{j=1}^{5}\left[b_{j} \theta_{j}(x)\right] \mathrm{d} x \text { subject to } \theta_{j}(x) \leq \bar{\theta}_{j} \text { for all } j, x \text {, and } \sum_{j=1}^{5} \theta_{j}(x)=x \text { for all } x,
$$

and this will be minimised by a strategy which minimises

$$
\sum_{j=1}^{5}\left[b_{j} \theta_{j}(x)\right] \text { subject to } \theta_{j}(x) \leq \bar{\theta}_{j} \text { for all } j \text { and } \sum_{j=1}^{5} \theta_{j}(x)=x
$$

for each $x \in[0, \bar{x}]$. Now, let us order instruments in roman numerals from smallest to largest $b_{j}$, so that instrument $i$ has the smallest $b_{j}$, instrument $i i$ has the next smallest, all the way to instrument $\mathrm{v}$ which has the largest $b_{j}$. Then Eq. (8) will clearly be minimised by a layered financial strategy which first utilises instrument $i$ until it is exhausted, i.e. $\theta_{i}(x)=\min \left(x, \bar{\theta}_{i}\right)$, then utilises instrument $i i$ until it is exhausted, i.e. $\theta_{i i}(x)=\min \left(x-\theta_{i}, \bar{\theta}_{i i}\right)$, then utilises instrument iii until it is exhausted, i.e. $\theta_{i i i}(x)=\min \left(x-\theta_{i}-\theta_{i i}, \bar{\theta}_{i i i}\right)$, etc.

Having demonstrated that a layered financial strategy is a solution to minimisation problem (7), we now provide simple formulae that characterise the structure of such a strategy.

Theorem 1 To minimise costs a government will use a layered financing strategy, where the $x$ th unit of expenditure will be financed by the instrument $j$ with the smallest $a_{j}+b_{j}(1-F(y))$.

Proof Let $\eta_{j}(y)$ denote the proportion of the $y$ th dollar of expenditure which is covered by instrument $j$. We may write $\theta_{j}(x)=\int_{0}^{x} \eta_{j}(y) \mathrm{d} y$ and $\bar{\theta}_{j}=\int_{0}^{\bar{x}} \eta_{j}(y) \mathrm{d} y$ and may now rewrite the cost function $C(\bar{\theta}, \theta)$ in terms of $\eta_{j}(y)$, as 


$$
\begin{aligned}
C(\eta) & =\sum_{j=1}^{5}\left[a_{j} \int_{0}^{\bar{x}} \eta_{j}(y) \mathrm{d} y+\int_{0}^{\bar{x}} \int_{0}^{x} f(x) b_{j} \eta_{j}(y) \mathrm{d} y \mathrm{~d} x\right] \\
& =\sum_{j=1}^{5}\left[a_{j} \int_{0}^{\bar{x}} \eta_{j}(y) \mathrm{d} y+\int_{0}^{\bar{x}} \int_{\bar{x}-y}^{\bar{x}} f(x) b_{j} \eta_{j}(y) \mathrm{d} x \mathrm{~d} y\right] \\
& =\int_{0}^{\bar{x}} \sum_{j=1}^{5} \eta_{j}(y)\left[a_{j}+b_{j}(1-F(y))\right] \mathrm{d} y .
\end{aligned}
$$

where both equalities comes from rearranging the order of integration/summation. Now we must choose $\eta_{j}(y)$ to minimise this cost function subject to the restrictions that $\sum_{j=1}^{5} \eta_{j}(y)=1$ for all $y, \eta_{j}(y) \geq 0$ for all $y, j$. This will clearly be minimised by choosing, for each $y \in[0, \bar{x}]$, a $j$ with the smallest $\left[a_{j}+b_{j}(1-F(y))\right]$ and then setting $\eta_{j}(y)=1$ and $\eta_{i}(y)=0$ for all $i \neq j$.

Theorem 1 allows us to find the risk financing strategy with the lowest expected opportunity cost by restricting attention to layered risk financing strategies and choosing the instrument for each layer at expenditure level $y$ to be the instrument $j$ with the smallest $a_{j}+b_{j}(1-F(y))$.

We may go one step further and characterise the optimal strategy in terms of opportunity cost multiples. An insurance multiple is defined as the premium divided by the expected claim payment and can be used as a proxy for the cost of insurance. We may extend this to the case of our full range of financing instruments by defining an opportunity cost multiple as the expected opportunity cost of an instrument divided by the expected expenditure financed by the instrument.

Definition 3 An average opportunity cost multiple for a given random expenditure profile using a specific instrument is the expected opportunity cost of financing that expenditure with that instrument divided by the expected expenditure to be financed.

Using the usual definition of the return period at expenditure level $y$ of $R(y)=\frac{1}{1-F(y)}$, and noting that covering a layer at expenditure level $y$ has an annual expenditure of $1-F(y)$, we may now state our final theoretical result

Corollary 1 To minimise costs, a government will use a layered financing strategy, where the expenditure at return period $R$ will be financed by the instrument $j$ with the smallest average opportunity cost multiple, $\mu_{j}(R)=a_{j} \times R+b_{j}$.

Corollary 1 is a trivial restatement of Theorem 1 . However, since this restatement does not involve the random expenditure $x$, it allows the contours of an average cost-minimising risk financing strategy to be understood even if the risk profile is not well understood. For example, using this corollary, it is possible to state that an average cost-minimising risk financing strategy will involve holding a contingency fund to cover all losses up to the 1-in3 -year loss (i.e. return period of 3 ), then to have a contingent line of credit up to the 1-in-7year loss (i.e. return period of 7), and then above that to have insurance. Whilst an understanding of the random expenditure profile $x$ will be necessary for implementing an 
actual strategy, this corollary may be useful for generating rules of thumb, as we demonstrate in the following section.

\section{Application}

The theoretical framework outlined in the section "A model of disaster risk finance" is now applied to a country case study, with results calculated based on country-specific risk profile and assumptions regarding the economic and financial situation. The hypothetical country is chosen to represent a small-island state with a small service-based economy heavily reliant on tourism and, while the country has relatively low recurrent disaster risk, it is highly exposed to potential catastrophic tropical cyclone and earthquake events. While the country can borrow easily and relatively cheaply in a non-disaster environment, following a large disaster, it would be both timely and expensive for the country to borrow in the commercial market. The country is assumed to have used their full allowance of concessionary loans and so, if a risk financing strategy includes the use of contingent credit, then this facility would reduce the amount the country can borrow on concessionary terms.

In applying the theoretical framework, we consider a "base strategy" which includes the use of debt-financed reserves, ex post budget reallocations and ex post borrowing. We then consider three alternative financing strategies where the government utilises a concessionary contingent credit facility ${ }^{11}$ (Strategy A), purchases market-based parametric insurance (Strategy B), or both (Strategy C). The theoretical framework is applied to each of these strategies based on the assumed parameters provided in Annex 1. Next, the total cost of each alternative strategy A, B and C is subtracted from the total cost of base strategy to show the potential cost savings of the government adopting each of the alternative strategies. Figure 1 presents the results of this calculation on an average basis and also shows the potential savings of each alternative strategy following a disaster event that is expected to occur with specific return period. The cost savings are presented in both USD millions and as a percentage of the total cost of the base strategy.

The results in Figure 1 indicate the following:

- Financing losses through contingent credit at concessional rates is cheaper on average relative to the base strategy. The inclusion of a concessionary contingent credit facility (Strategy A) results in a saving of USD 0.94 million on average (4.2 per cent of total expected cost), or USD 7.4 million (9 per cent) following disaster losses expected to be incurred once every 15 years.

${ }^{11}$ As outlined in the "Introduction", there are several contingent credit facilities available to governments. The specific instrument considered in the case study is the World Bank Development Policy Loan with Catastrophe Deferred Drawdown Option (CAT DDO). This facility is a pre-arranged line of credit that a country can draw upon in the aftermath of a natural disaster. Amounts drawn down are subject to repayment at the same (concessionary) interest rates as amounts borrowed through existing World Bank Development Policy Loans. The Cat DDO has a "soft trigger" (as opposed to a parametric trigger), where funds become available for disbursement after the declaration of a state of emergency due to a natural disaster. See here for more information: http://treasury.worldbank.org/bdm/pdf/Handouts_Finance/CatDDO_Product_Note.pdf. 


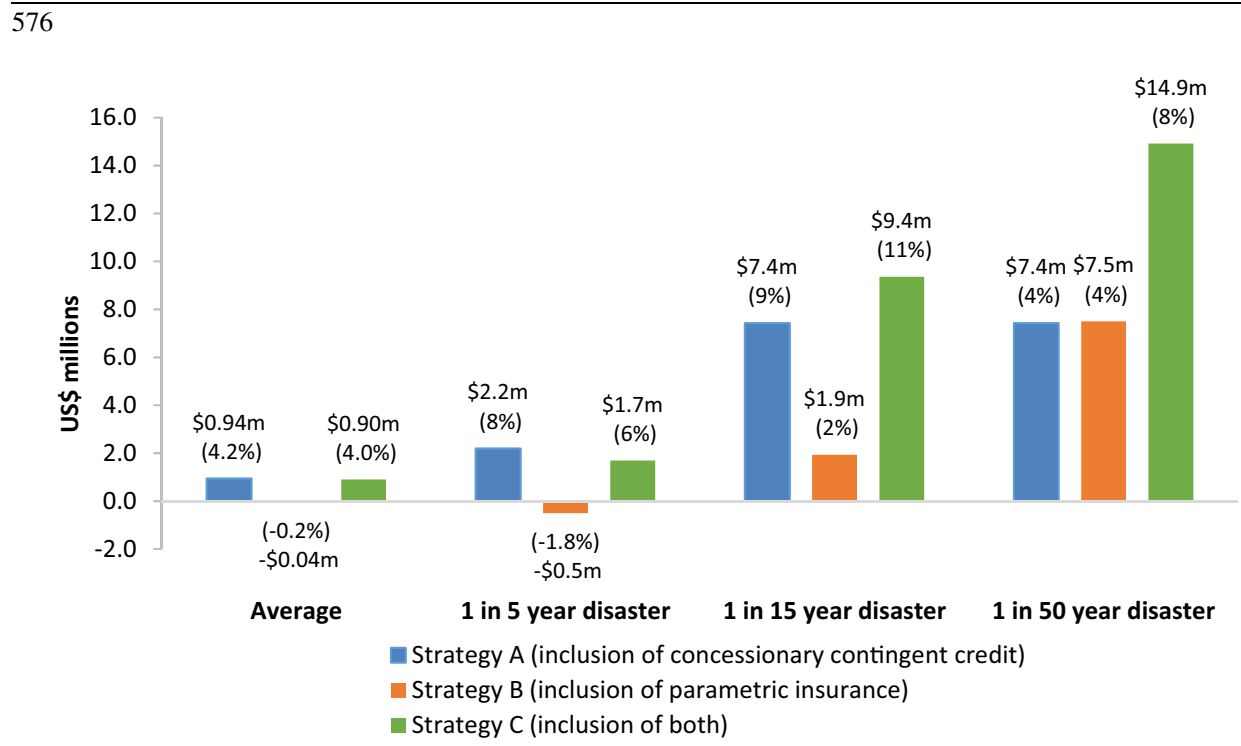

Figure 1. Cost savings of strategies $\mathrm{a}, \mathrm{b}$ and $\mathrm{c}$ relative to base strategy.

- When insurance is considered as part of the strategy (Strategy B), costs are higher on average (increased costs of USD 0.04 million), but the savings following disasters at high return periods are significant. For example, the purchase of insurance for a premium of USD 0.5 million (as detailed in Annex 1) leads to a saving of USD 7.5 million (4 per cent) following a 1-in-50-year loss. While Strategy B has a higher average cost than Strategy A, the government may consider this strategy if it has an aversion to budget volatility, and therefore would be willing to pay to limit the potential costs of financing disaster at more extreme return periods.

- If both concessionary contingent credit and insurance are used together (Strategy C), then the government receives the benefit of the concessionary credit at the low return periods (for example a saving of USD 1.7 million or 6 per cent for a 1-in-5-year loss), and even greater savings at more extreme return periods when compared to using insurance alone. The results indicate that the savings associated with the use of concessionary contingent credit are sufficient to offset the additional average cost of purchasing insurance, and the use of both instruments together can result in savings of USD 14.9 million (8 per cent) following a 1-in-50 year disaster.

In addition to considering the expected cost savings on an average basis and following disasters at varying return periods, the theoretical framework allows the calculation of the marginal opportunity cost of each financing instrument at all layers of risk. Presenting the marginal opportunity cost as a multiple of the average annual loss in each corresponding layer of risk provides a simple comparison of the relative cost of each instrument at all return periods, as shown in Figure 2. For simplicity, the "opportunity cost multiples" of only reserves, contingent credit and insurance are shown, although it is possible to calculate the cost multiples for all five instruments included in the theoretical framework. 


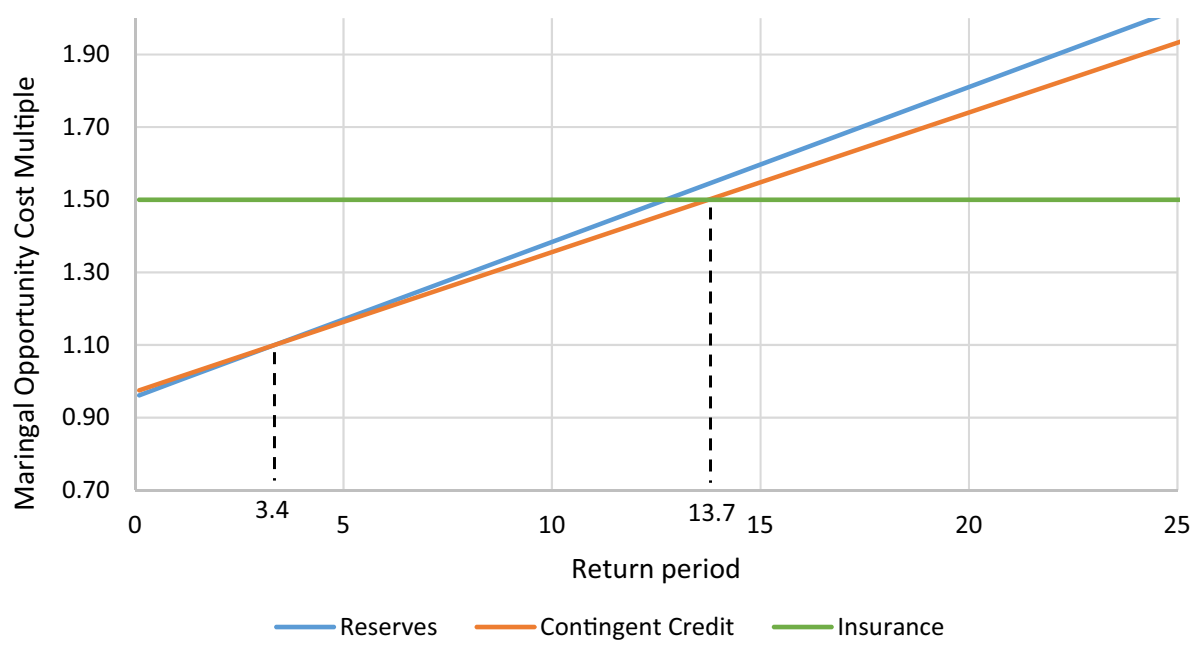

Figure 2. Marginal opportunity cost multiples of reserves, ex post debt and insurance.

Figure 2 indicates that the cheapest strategy involving the three instruments shown is to use a prefinanced reserve fund to finance losses up to the 1-in-3.4-year return period, then contingent credit to finance losses up to the 1-in-13.7-year return period, and to use insurance to finance more extreme disasters. The marginal opportunity cost multiples of reserves and contingent credit are both upward sloping, due to the increasing opportunity cost of holding a sufficiently large reserve fund to finance more extreme losses, and for contingent credit, there is an increasing opportunity cost due to the reduction in the cheap direct credit available to government. The cost of insurance is assumed to be a fixed multiple of 1.5 multiplied by the expected loss. This is a simplistic approach and does not reflect how insurance markets price risk; however, this approach is taken to allow easy comparison of the cost of insurance with the other financial instruments. As discussed further in the following section, in reality, the pricing multiple of insurance is likely to increase with the layer of risk being insured. While this may lead to other instruments (such as ex post debt) being cheaper than insurance at high return periods, an aversion to budget volatility or any public financial management or commitment problems could still make insurance attractive, even at high return periods.

The case study provides an application of the theoretical framework presented in the section "A model of disaster risk finance". A tiered strategy of using different financing instruments offers the greatest average opportunity cost savings when compared to relying on only financing disaster losses through ex post financing instruments such as reserves, ex post budget reallocations and ex post borrowing. Moreover, the strategy which utilises both concessionary contingent credit and parametric insurance leads to positive savings at all loss severities, with savings increasing with the severity of the loss. It should be noted that the results of the analysis are heavily dependent on the assumed economic and financial conditions, and the underlying disaster risk faced. A different set of assumptions may change the specific combination of financial instruments, including their order of use, that define the financial strategy with the lowest average cost. 


\section{Discussion of results}

The proposed framework can inform the decision of how a government structures its financing of a specific contingent liability, and what the cost of such financing could be, in terms of the opportunity cost and the opportunity cost multiple. It allows ex ante evaluation of risk financing strategies, and this can be useful for governments and international donors interested in cost-effectively financing contingent liabilities. The most important, and powerful, restriction which enables this analysis is the separation of the economic impact of expenditures from the economic cost of financing. Other than the issue of delayed response, the above framework totally ignores the former issue and focuses on the latter. This is both a strength and a weakness. The strength lies in the ability to directly compare the cost of financing the defined contingent liability using alternative risk financing strategies which can be matched to government objectives, whether that be to minimise average costs, minimise costs of financing a disaster of particular magnitude, or other financial objectives. However, the analysis cannot shed light on what a government "should" do in the aftermath of a disaster, or what contingent liability a government "should" take on. It cannot suggest whether governments should prioritise post-disaster reconstruction of bridges or compensation payments to affected households, nor by itself can it suggest whether governments should mount small or large responses. As such it can complement, rather than replace, other evaluation approaches such as analysis of financing gaps and the full economic costs of these gaps.

There are also numerous limitations which must be considered when applying the methodology. In practice, these limitations mean that applying the above methodology and selecting the strategy with the lowest average opportunity cost will, in most cases, not be appropriate. Rather the quantitative analysis above needs to be interpreted appropriately and combined with expert judgement for it to be useful in practice.

In particular, our main theoretical results rely on linearity assumptions (such as the assumption that post-disaster credit is subject to the same marginal interest rate regardless of the amount of post-disaster borrowing) and an assumption that each instrument has unlimited availability (such as the assumption that government can make unlimited emergency budget reallocations). Together these assumptions mean that the optimal financing instrument for a given return period does not depend on how much each instrument is being used at other return periods, a kind of separability. These assumptions are critical for the theoretical results in the section "A model of disaster risk finance", but are unlikely to hold in reality. For example, large post-disaster borrowing for a small economy may substantially affect marginal interest rates, ${ }^{12}$ and anecdotal evidence suggests that typically governments are only able to reallocate a small percentage of the public budget following disaster events. ${ }^{8}$ In such circumstances, linear average marginal costs may not be calculable, since the average marginal cost at a given return period would depend on the amount the instrument is utilised at other return periods, but it is still possible to use variants of the formulae for opportunity cost presented in the section "Opportunity cost of risk financing instruments" to calculate opportunity costs reflecting the various non-linearities and constraints, and compare opportunity costs of different

\footnotetext{
${ }^{12}$ Cordella and Levy Yeyati (2015).
} 
feasible strategies. Indeed this is what we have done in the section "Application", where we have assumed that government is only able to reallocate 2 per cent of annual government expenditure to financing post-disaster expenditures in all strategies.

One particularly simplistic assumption is that the cost of insurance is just a fixed multiple of the expected loss. However, as with the other linearity assumptions, it is possible to replace the cost formulae presented for insurance in the section "Opportunity cost of risk financing instruments" with more realistic formulae and calculate opportunity costs under these alternative assumptions. If the variability of the expected losses were to be taken into account in the calculation of the insurance premium, the effective pricing multiple would be expected to be greater for insurance that provides cover for high-severity low-frequency (and therefore more variable) events when compared to insurance that provides cover for low-severity high-frequency events. In the case study presented in the section "Application", the insurance product covers a mid-layer of risk (between a 1-in-10 and 1-in-30-year event), and the pricing multiple is assumed to be 1.72. In another application of the framework, Clarke et al. ${ }^{13}$ assume a much lower pricing multiple of 1.35 to reflect the fact the insurance product being considered in that case is intended to cover a much lower layer of risk.

While Gollier ${ }^{14}$ and more recently, Bevan and Adam $^{9}$ find that a strategy of timediversification (or self-insurance) is more cost-effective than insurance, the framework indicates that under certain financial and economic conditions, such as a sharp increase in the marginal interest rate following a disaster event or where there is a long delay in organising $e x$ post borrowing, insurance may in fact be a cost-effective way to finance disaster losses. However, such conditions may only exist in the immediate aftermath of a disaster, and so the framework supports the suggestion of Clarke and Dercon ${ }^{15}$ that insurance may be preferable where there is an aversion to budget volatility, but only for immediate post-disaster funding needs rather than for reconstruction costs which are usually funded at a later point. In addition, there are usually significant fixed costs associated with sovereign insurance products, especially for those aimed at low- and middle-income countries, where data to price risk are usually scarce. As a result, where parametric insurance has been offered to low- and middleincome countries, it is usually based upon a sophisticated catastrophe risk model which is used to calculate an estimate of the disaster risk faced. Examples include the insurance products offered through the Caribbean Catastrophe Risk Insurance Facility (CCRIF), the Pacific Catastrophe Risk Assessment and Financing Initiative (PCRAFI), and the Africa Risk Capacity (ARC). In such examples, significant upfront investment is required in the data collection and analysis, and the building of the model which the insurance product is based upon. These costs will ultimately be borne either by international donors, or will be passed onto the eventual policyholders through the insurance premiums charged. Where this and other fixed costs are expected to be borne by the policyholder, this should be taken into account in the assumed cost of insurance. Again this cannot be easily incorporated into the marginal opportunity cost charts, but can be incorporated into comparative analysis of opportunity costs for different strategies.

\footnotetext{
${ }^{13}$ Clarke et al. (2016).

14 Gollier (2003).

15 Clarke and Dercon (2016).
} 
Many assumptions are made in the application of the framework (see Annex 1 for assumptions relating to the case study), and so an important part of analysing the results is sensitivity analysis to understand the main sources of uncertainty in the results. Clarke et $a l .{ }^{13}$ perform such a sensitivity analysis for a further application of the framework and find that optimal risk financing strategies can be quite sensitive to the economic and commercial environment, but these sensitivities are consistent with economic intuition. While these insights are useful, the findings of such a sensitivity analysis will be specific to the context in which the framework is being applied, and so such an analysis must be completed in each application.

The findings of this paper, that different risk financing strategies do have different costs to government, may appear to be inconsistent with the Modigliani-Miller theorem on capital structure irrelevance for firms. However, the assumptions of this theorem do not hold for governments faced with disaster risks and free to decide both when and how to finance these costs. In particular, the degree to which taxes impose deadweight losses on the private sector is likely to be different before or after a potential disaster, and therefore, decisions over the extent to which funds are raised before or after potential disasters and how much of the risk is hedged will affect the financial efficiency, as presented above.

Finally, it is noted that, while the framework provides a useful way to compare the economic opportunity costs of each financing instrument, there are other benefits and considerations of each financial instrument which cannot be taken into account in a quantitative analysis. For example, Clarke and Wren-Lewis ${ }^{16}$ argues that risk transfer instruments such as insurance solve commitment problems faced by governments, allowing them to implement faster, better-targeted response without the need for massive institutional development in terms of strong public financial management. These benefits have not been included in the above methodology, but such considerations may be very important factors for governments when considering different financial and budgetary instruments.

\section{Conclusion}

This paper proposes a framework for evaluating the cost and timing of alternative sovereign risk financing strategies, which are key factors for governments to consider when setting appropriate strategies to ensure financial resilience to disasters. The paper makes a contribution to the literature in this area by suggesting simple quantitative formulae for capturing the opportunity cost of risk financing instruments, allowing governments to directly compare the relative costs of different sovereign risk financing strategies. It also presents a methodology for calculating the "cost multiples" for a range of instruments at different return periods, which may be useful in communicating these costs to decisionmakers.

The case study shows that the results are intuitive and further applications have shown how the methodology is amenable to sensitivity analysis. ${ }^{17}$ The framework provides

\footnotetext{
${ }^{16}$ Clarke and Wren-Lewis (2016).

${ }^{17}$ World Bank (2016).
} 
evidence to support the tiered approach to sovereign risk financing and provides a methodology to allow governments to select a risk financing strategy based on their objectives (for example to minimise average costs or minimise the costs for a disaster of given magnitude). The proposed framework allows the government to consider the costs of funding their contingent liability to disasters using different combinations of financial instruments, and to minimise this cost based on their preferences towards risk.

There are some aspects of disaster risk financing that this methodology does not adequately capture and which would merit further research. First, this analysis has been presented for risk transfer products which perfectly match the government's expenditure rules, although, in practice, governments sometimes choose to use risk transfer instruments with payment schedules that do not precisely match planned expenditures. Extending the analysis to allow for imperfect correlation between expenditure profiles and risk transfer instruments would be useful. Second, many of the assumptions required for practical implementation of this methodology, such as the opportunity cost of budget reallocations, or the cost of delayed response, are quite poorly understood and would merit further research. Third, a further potential application of the calculated cost multiples is the comparison of investing in financial protection to investments in physical disaster risk reduction and mitigation measures. While the inclusion of such investments would require careful interpretation of the results, the calculated cost multiples are similar in nature to calculations of the net present value of potential future investments and so, such an analysis may be possible. Finally, this paper only addresses the financial cost side of disaster risk finance systems and would be usefully complemented by analysis of the economic impact of different expenditure profiles.

\section{References}

Benson, C. and Clay, E. (2004) Understanding the Economic and Financial Impacts of Natural Disasters, Washington, DC: World Bank.

Bevan, D. and Cook, S. (2014) Public expenditure following disasters, Policy Research Working Paper 7355, World Bank SDRFI Impact Appraisal Project.

Bevan, D. and Adam, C. (2016) Financing the reconstruction of public capital after a natural disaster. World Bank Policy Research Working Paper Series, Washington, DC: World Bank.

Buchanan, J. (2008) 'Opportunity cost', in S.N. Durlauf and L.E. Blume (eds), The New Palgrave Dictionary of Economics, 2nd ed., Basingstoke, Hamps./New York: Palgrave Macmillan.

Clarke, D., Cooney, N., and Edwards, A. (2016) A methodology to assess indicative costs of risk financing strategies for scaling up Ethiopia's Productive Safety Net Programme, World Bank Policy Research Working Paper 7719, World Bank.

Clarke, D. and Dercon, S. (2016) Dull Disasters? How Planning Ahead Will Make a Difference, Oxford: Oxford University Press.

Clarke, D. and Mahul, O. (2011) Disaster risk financing and contingent credit: a dynamic analysis, World Bank Policy Research Working Paper Series, Paper 5693, Washington, DC: World Bank.

Clarke, D. and Wren-Lewis, L. (2016) Solving commitment problems in disaster risk finance, World Bank Policy Research Working Paper No. 7720, Washington, DC: World Bank.

Cordella, T. and Levy Yeyati, E. (2015) 'CATalytic insurance: the case of natural disasters', Oxford Review of Economic Policy 31 (3-4): 330-349.

de Janvry, A., del Valle, A., and Sadoulet, E. (2016) Insuring growth: the impact of disaster funds on economic reconstruction in Mexico, World Bank Policy Research Working Paper No. 7714,, Washington, DC: World Bank. 
Goes, A. and Skees, J. (2003) 'Financing natural disaster risk using charity contributions and ex ante index insurance', paper presented at the American Agricultural Economics Association (AAEA) 2003 Annual meeting, 27-30 July, Montreal, Canada.

Gollier, C. (2003) 'To insure or not to insure?: An insurance puzzle', The Geneva Papers on Risk and Insurance Theory 28(1): 5-24.

GFDRR and World Bank Group (2014) Financial Protection Against Disasters: an Operational Framework for Disaster Risk Financing and Insurance, Washington, DC: World Bank.

Ghesquiere, F. and Mahul, O. (2007) Sovereign natural disaster insurance for developing countries: a paradigm shift in catastrophe risk financing, World Bank Policy Research Working Paper Series, Paper 4345, Washington, DC: World Bank.

Ghesquiere, F. and Mahul, O. (2010) Financial protection of the state against natural disasters: a primer, World Bank Policy Research Working Paper 5429, Washington, DC: World Bank.

Gurenko, E. and Mahul, O. (2003) Combining insurance, contingent debt and self-retention an optimal corporate risk financing strategy, World Bank Working Paper 3167, Washington, DC: World Bank.

Kreps, R. (1990) 'Reinsurer risk loads from marginal surplus requirements', Proceedings of the Casualty Actuarial Society 77: 196-203.

Lakdawalla, D. and Zanjani, G. (2006) Catastrophe bonds, reinsurance, and the optimal collateralization of risk transfer, NBER Working Paper 12742, Cambridge, MA: National Bureau of Economic Research.

Lee, J.-P. and Yu, M-T. (2002) 'Pricing default-risky CAT bonds with moral hazard and basis risk', The Journal of Risk and Insurance 69(1): 25-44.

Lee, J-P. and $\mathrm{Yu}, \mathrm{M}-\mathrm{T}$. (2007) 'Valuation of catastrophe reinsurance with catastrophe bonds', Insurance: Mathematics and Economics 41(2): 264-278.

Linnerooth-Bayer, J. and Mechler, R. (2007) 'Disaster safety nets for developing countries: Extending publicprivate partnerships', Environmental Hazards 7(1):54-61.

World Bank (2016) Evaluating Sovereign Disaster Risk Finance Strategies: Guidance and Case Studies, Washington, DC: World Bank Group.

\section{Annex 1}

Assumptions relevant to the application of the theoretical framework to the case study as outlined in the section "Application" are as follows. Note all interest rates are quoted in USD and not local currency.

\begin{tabular}{|c|c|c|}
\hline Description & Parameter & Assumed value \\
\hline Distribution of post-disaster expenditures & $x$ & $\begin{array}{l}\text { Based on an example per-event emergency loss } \\
\text { distribution developed by a commercial } \\
\text { vendor and the assumption that the } \\
\text { government funds } 100 \% \text { of all disaster losses }\end{array}$ \\
\hline $\begin{array}{l}\text { Marginal interest rate on sovereign debt, assumed } \\
\text { to be average borrowing rate on government } \\
\text { debt portfolio }\end{array}$ & $i(=\delta)$ & $5.5 \%$ \\
\hline Size of reserve fund & $\bar{\theta}_{1}$ & USD $1.5 \mathrm{~m}$ \\
\hline Investment return on unspent reserves & $r$ & $1 \%$ \\
\hline Amount of concessionary contingent credit & $\bar{\theta}_{2}$ & USD $20 \mathrm{~m}$ \\
\hline Interest rate on contingent credit & $c$ & $2.5 \%$ \\
\hline Arrangement fee for contingent credit & $\kappa$ & $1 \%$ \\
\hline Treatment of outstanding concessionary loans & $\beta$ & 1 \\
\hline Amount of budget reallocation available & $\bar{\theta}_{3}$ & USD $19.5 \mathrm{~m}$ \\
\hline $\begin{array}{l}\text { Social rate of return on projects not funded due to } \\
\text { reallocation of budgets }\end{array}$ & $h$ & $\begin{array}{l}12 \% \text { (see }{ }^{10} \text { for one approach to estimating this } \\
\text { assumption) }\end{array}$ \\
\hline
\end{tabular}




\begin{tabular}{|c|c|c|}
\hline Description & Parameter & Assumed value \\
\hline Marginal interest rate on ex post borrowing & $e$ & $7 \%$ \\
\hline Repayment term of ex post borrowing & $n$ & 10 \\
\hline $\begin{array}{l}\text { Annual effective increase in cost of planned } \\
\text { expenditures if financed through ex post } \\
\text { borrowing }\end{array}$ & $d$ & 0.4 \\
\hline $\begin{array}{l}\text { Delay in financing planned expenditures if } \\
\text { financed through ex post borrowing }\end{array}$ & $t$ & 9 months \\
\hline Distribution of insurance claim payments & $\theta_{5}(x)$ & $\begin{array}{l}\text { Attachment point: } 1 \text { in } 10 \text { year event } \\
\text { Exhaustion point: } 1 \text { in } 30 \text { year event } \\
\text { Ceding } \%: 10 \% \text { (based on pricing multiple and } \\
\text { fixed premium of USD } 0.5 \mathrm{~m} \text { ) }\end{array}$ \\
\hline Insurance pricing multiple & $m$ & 1.5 \\
\hline
\end{tabular}

\section{About the Authors}

Daniel J. Clarke works in the United Kingdom Government Actuary's Department. Over the last decade, he has worked with 40 developing country governments to develop solutions for enhanced financial protection against disasters. He has a first class degree from Cambridge University in Mathematics in Computer Science and a DPhil. in Economics from the University of Oxford, and is a Fellow of the Institute of Actuaries.

Olivier Mahul is Global Lead and Manager of the Disaster Risk Financing and Insurance Program at the World Bank. The Program provides analytical and advisory services on financial protection against natural disasters in more than 50 countries. He holds a Ph.D. in Economics from the Toulouse School of Economics and post-doctorates from Wharton Business School and University of California at Berkeley. He has authored more than 40 publications in international journals and two books on disaster risk finance and agricultural insurance.

Richard Poulter is a Senior Disaster Risk Financing and Insurance (DRFI) consultant, working primarily for the World Bank Group-GFDRR DRFI Program to help governments develop greater financial protection against disasters. He is a Fellow of the U.K. Institute and Faculty of Actuaries and also holds a Master's degree in Disaster Management from the University of Copenhagen.

Tse-Ling Teh is a researcher in the Grantham Research Institute on Climate Change and the Environment at the London School of Economics and Political Science. Her research considers individual behaviour and welfare under risk. She is an Associate of the Institute of Actuaries Australia and holds a PhD. in Sustainable Development from Columbia University. 
Open Access This article is distributed under the terms of the Creative Commons Attribution 4.0 International License (http://creativecommons.org/licenses/by/4.0/), which permits unrestricted use, distribution, and reproduction in any medium, provided you give appropriate credit to the original author(s) and the source, provide a link to the Creative Commons license, and indicate if changes were made. 